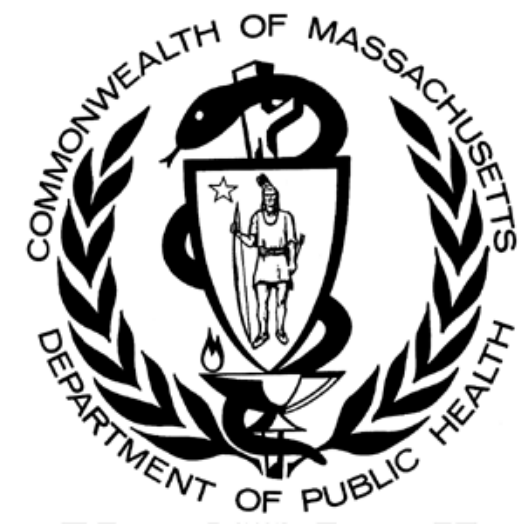

\title{
A Health Profile of Massachusetts Adults by Sexual Orientation Identity: Results from the 2001-2006 Behavioral Risk Factor Surveillance System Surveys
}

\author{
Prepared by \\ K.J. Conron, ScD1, MPH, M.J. Mimiaga2,3, ScD, MPH, S.J. Landers4,5, JD, MCP \\ for the Massachusetts Department of Public Health
}

November 2008 


\section{SUMMARY}

A growing body of research indicates that health disparities exist between gay/lesbian/bisexuals and heterosexuals. For the first time, population-based estimates of sexual orientation differences in adult health are available in the Commonwealth of Massachusetts. This report used data collected for the 2001-2006 Massachusetts Behavioral Risk Factor Surveillance System surveys to compare self-reported health behavior and status among $(n=38,910)$ heterosexual/straight, gay/lesbian/homosexual, and bisexual adults ages $18-64$. Most (97.1\%) self-identified as heterosexual or straight, while $1.9 \%$ identified as gay, lesbian or homosexual, and $1.0 \%$ as bisexual.

Results suggest that sexual orientation differences exist with respect to access to health care, overall health status, cancer screening, chronic health conditions, mental health, substance use including tobacco smoking, sexual health, and violence victimization. While gay/lesbian/homosexual adults evidenced poorer health and greater risk than straight/heterosexuals across several health domains, poorer health was observed most often for bisexuals. The health profile of gay/lesbian/homosexual residents was poorer than that of heterosexual/straight residents on: self-reported health; disability-related activity limitation; asthma; current and past tobacco smoking; anxious mood; 30-day binge drinking and substance use; and lifetime sexual assault victimization. In addition, lesbian/homosexual women were more likely to be obese than their heterosexual/straight female peers. Bisexual residents faired worse than heterosexual/straight residents in terms of: access to health insurance, as well as medical and dental providers; heart disease; anxious and depressed moods, 12-month suicidal ideation; current tobacco smoking, and lifetime and 12-month sexual assault victimization. In addition, bisexual women were more likely to report disability-related activity limitation, 30-day illicit drug use, and lifetime intimate partner violence victimization than heterosexual/straight women.

In several areas (prostate-specific antigen testing; lifetime mammography and 3year cervical cancer screening; diabetes; and 12-month intimate partner violence victimization), no statistically significant sexual orientation differences were observed. In a few domains, gay/bisexual/homosexuals were engaged in more health protective behavior than straight/heterosexuals. Gay/lesbian/homosexuals and bisexuals were more likely than heterosexuals to have been ever tested for HIV than their straight/heterosexual counterparts. In addition, gay/homosexual men were less likely to be obese or overweight compared to straight/heterosexual men. They were also more likely to obtain lifetime colorectal cancer screening and to report recent condom use.

Information on health disparities can inform how public health resources are allocated to improve health, including identifying areas for intervention development and future research. As research continues, Massachusetts' public health programs should begin to address the sexual orientation-related disparities identified in this report. An emphasis on the health needs of bisexuals in the Commonwealth is indicated by our findings. 


\section{INTRODUCTION}

A growing body of research indicates that there are many areas where health disparities exist between gay/lesbian/bisexual and heterosexual populations (GLMA, 2001; Makadon, Mayer, Potter \& Goldhammer, 2007; Meyer \& Northridge, 2007; Wolitski, Stall \& Valdiserri, 2008). These include health care access, mental health, tobacco, alcohol, and other drug use, sexual health, and violence victimization (Bye, Gruskin, Greenwood, Albright \& Krotki, 2005; Cochran et al., 2000; Cochran, Sullivan, \& Mays, 2003; Diamant, Wold, Spritzer \& Gelberg, 2000; Gilman et al., 2001; Greenwood et al., 2005; Heck, Sell, \& Gorin, 2006; Lampinen et al., 2008; Moracco, Runyan, Bowling \& Earp, 2007). Information on disparities can inform how public health resources are allocated to improve health. This report is the first ever to compare selfreported health behavior and status among heterosexual/straight, gay/lesbian/homosexual, and bisexual Massachusetts adults.

\section{METHODS}

The Behavioral Risk Factor Surveillance System (BRFSS) is a collaborative effort between the US Centers for Disease Control and Prevention (CDC) and state departments of public health (CDC, 2006). This annual telephone survey of health draws a stratified probability household sample of adults using random digit dial methods. The CDC provides core survey questions; however, states often collect additional data. In 2001, Massachusetts began to measure sexual orientation identity with the following item: "Do you consider yourself to be: Heterosexual or straight, Homosexual or gay (if male), lesbian (if female), Bisexual, or Other" (MDPH). "Don't know" responses and refusals were recorded by the interviewer. Many survey items remain the same year after year, thus, permitting data to be combined over several years.

Between 2001 and 2006, 41,548 Massachusetts residents, ages 18-64 were asked to provide information about their sexual orientation identity. A minority (3.6\%) of survey participants declined or refused to provide a response -- some $(0.5 \%)$ answered that they "didn't know", and some $(0.5 \%)$ selected other as their sexual orientation identity. (See Appendix 1 for additional information about non-response.) These survey participants were excluded from our analyses, leaving 39,417 Massachusetts residents who reported a straight/heterosexual, gay/lesbian/homosexual, or bisexual identity. 38,910 straight/heterosexual, gay/lesbian/homosexual, or bisexual residents answered questions about their age, sex, race-ethnicity, educational attainment, and employment status and were included in our analyses. 
Sampling weights provided by the Massachusetts Department of Public Health were used to address different probabilities of selection and survey participation. Participation rates ranged from a low of $40 \%$ to a high of $70 \%$, with most falling in the range of $62-65 \%$ (MDPH, 2001-2006). Surveys were conducted in English, Spanish and Portuguese. Analyses were conducted with SAS statistical software (SAS Institute, 2003). SAS survey procedures were used to produce $95 \%$ confidence intervals $(\mathrm{Cl})$ that appropriately reflect the stratified sampling design.

Tables 1 and 2 provide descriptive information, in the form of crude percentages, about the socio-demographic and health characteristics of residents by sexual orientation identity. The reader is advised that the crude percentages, also called prevalence proportions, do not account for differences in the socio-demographic composition of each sexual orientation group. Gay/lesbian/homosexuals have somewhat more formal education than straight/heterosexuals. People with more education usually have better health. Bisexuals are younger, on average, than straight/heterosexuals. Younger people tend to have fewer physical health problems, but may be heavier users of alcohol, have more sexual partners and so forth than older people. Comparisons that do not take these differences into consideration are biased (under or over-estimate actual differences between sexual orientation groups).

Table 3 provides odds ratios (OR) and 95\% confidence intervals $(\mathrm{Cl})$ that compare health characteristics of gay/lesbian/homosexual and bisexual residents to those of straight/heterosexuals, while adjusting for socio-demographic differences between groups. Adjusted odds ratios are estimates of differences between sexual orientation groups that are treated as if they had about the same age, sex, racial-ethnic, and educational composition. Statistical adjustment permits less biased comparisons to be made between groups. Multivariable binary or multinomial logistic regression procedures were used to generate $\mathrm{OR}$ and $95 \% \mathrm{Cl}$. Statistically significant odds ratios are indicated in bold type.

In order to determine whether associations between sexual orientation and health varied in magnitude or direction between female and male participants, we tested for effect modification by sex. Interaction terms between sex and dummy variables for gay/lesbian/homosexual and bisexual were included in multivariable logistic regression models that also contained the main effects of sex, sexual orientation, age, raceethnicity, and educational attainment. When an interaction term was statistically significant, sex-stratified estimates were generated. Odds ratios and $95 \% \mathrm{Cl}$ from sexstratified models are provided when they achieved statistical significance. All tests of statistical association were two-tailed and used an alpha of 0.05 . For more information about terms and definitions used in this report, please see Appendix 2. 


\section{RESULTS}

\section{Sexual Orientation}

- $97.1 \%$ of adults identified themselves as heterosexual or straight, while $1.9 \%$ self-identified as gay, lesbian or homosexual, and $1.0 \%$ as bisexual.

\section{Access to Health Care}

Health insurance

- $10 \%$ of straight/heterosexuals and $12 \%$ of gay/lesbian/homosexuals reported being uninsured while $22 \%$ of bisexual adults reported being without health insurance.

- Bisexuals were less likely to report having health insurance than straight/heterosexuals (OR 0.43; 95\% Cl 0.28, 0.66).

- There were no statistically significant differences between gay/lesbian/homosexuals and straight/heterosexuals.

Regular healthcare provider

- $14 \%$ of straight/heterosexual, $15 \%$ of gay/lesbian/homosexual, and $32 \%$ of bisexual adults reported being without a regular healthcare provider.

- Bisexuals were less likely to report having a regular provider than straight/heterosexuals (OR 0.40; $95 \% \mathrm{Cl} 0.28,0.58)$.

- There were no statistically significant differences between gay/lesbian/homosexuals and straight/heterosexuals.

Dental care

- More bisexual adults (37\%) reported that they had not been to a dentist or a dental clinic for a cleaning in the prior 12 months than straight/heterosexual and gay/lesbian/homosexual (both $22 \%$ ).

- Bisexuals were less likely to report having been for a dental cleaning in the prior

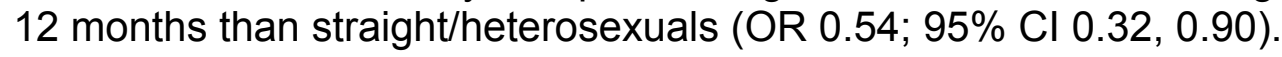

- There were no statistically significant differences between gay/lesbian/homosexuals and straight/heterosexuals. 


\section{Overall Health Status}

Self-reported health

- $10 \%$ of straight/heterosexual, $11 \%$ of gay/lesbian/homosexual, and $25 \%$ of bisexual adults reported that their health was either fair or poor.

- Gay/lesbian/homosexuals were more likely to report having fair/poor health than straight/heterosexuals (OR 1.45; 95\% Cl 1.06, 1.98).

- Bisexuals were more likely to report having fair/poor health than straight/heterosexuals (OR 4.44; 95\% Cl 2.76, 7.13).

Figure 1: Health Outcome Differences: Self-reported Health

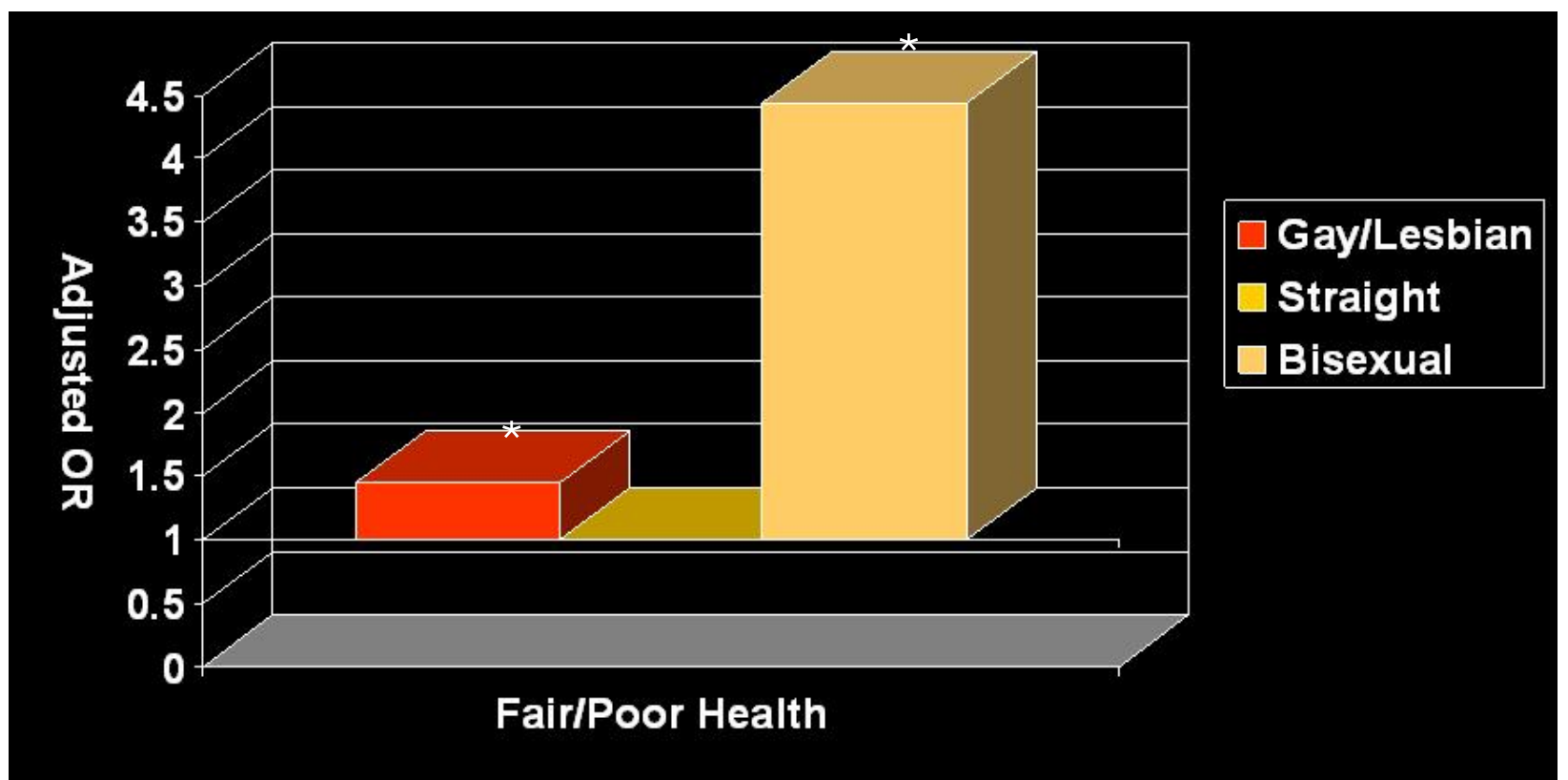

${ }^{*} P<0.05$, Referent group: straight

Activity limitation

- $15 \%$ of straight/heterosexual, $22 \%$ of gay/lesbian/homosexual, and $33 \%$ of bisexual adults reported any limitation in activity because of a physical, mental or emotional disability.

- Gay/lesbian/homosexuals were more likely to report a disability-related activity limitation compared to straight/heterosexuals (OR 1.78; 95\% Cl 1.42, 2.25). 
- The odds of being limited by a disability were greater for bisexual (OR 5.26, 95\% $\mathrm{Cl} 3.48,7.95)$ than straight/heterosexual women, but did not differ between bisexual and straight/heterosexual men.

Figure 2: Health Outcome Differences: Activity Limitation Due to Disability

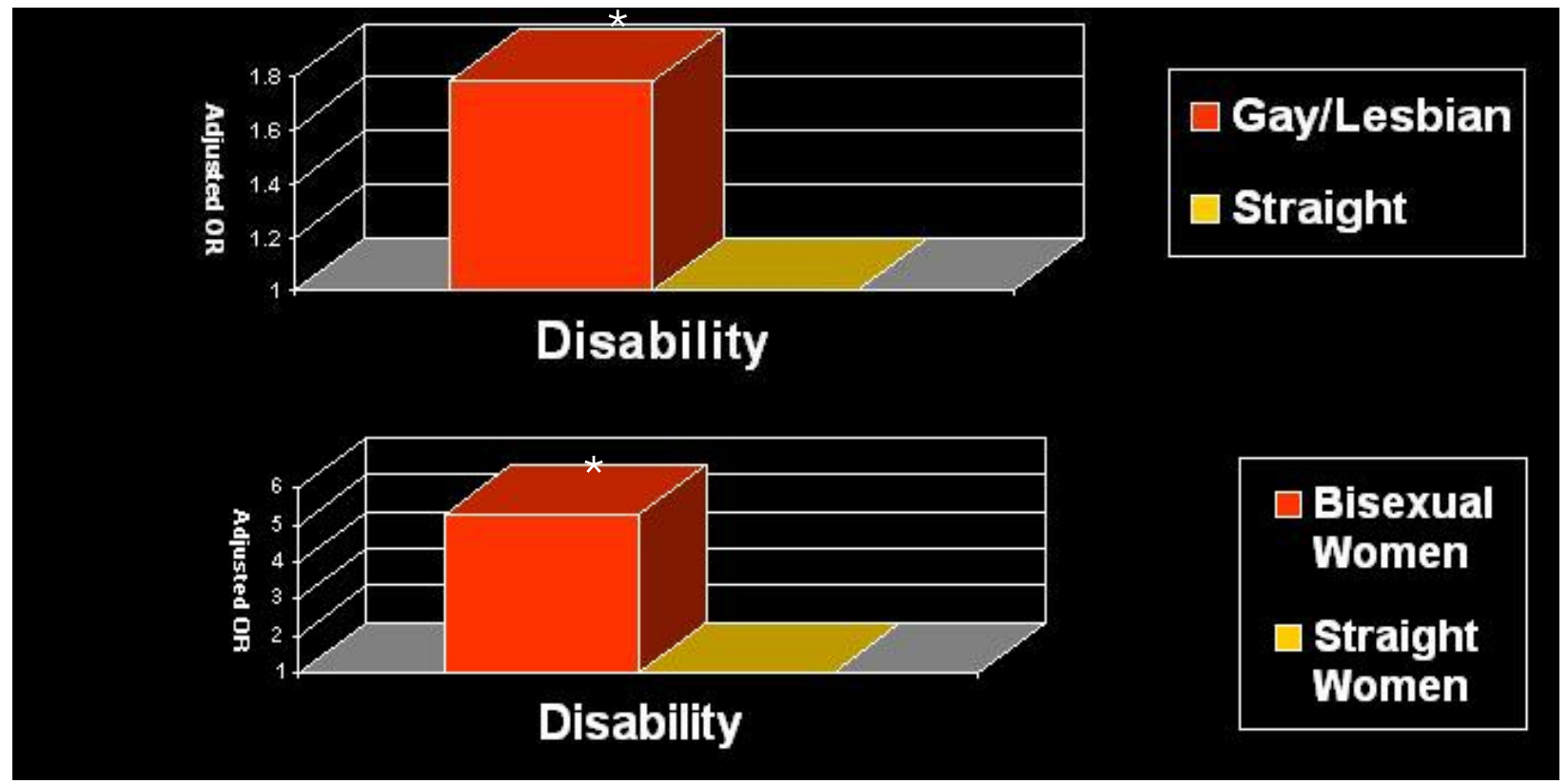

${ }^{\star} P<0.05$, Referent group: straight

Weight

- $55 \%$ of straight/heterosexual, $51 \%$ of gay/lesbian/homosexual, and $44 \%$ of bisexual adults were either overweight or obese at the time of survey completion ${ }^{1}$.

- Lesbian/homosexual women were more likely to be obese versus at a "normal" weight compared to straight/heterosexual women (OR 2.23; 95\% Cl 1.57, 3.18).

- In contrast, gay/homosexual men were less likely to be overweight (OR 0.57 ; $95 \% \mathrm{Cl} 0.43,0.75$ ) or obese (OR $0.42 ; 95 \% \mathrm{Cl} 0.28,0.62$ ) versus at a "normal" weight than straight/heterosexual men.

- There were no statistically significant differences between bisexuals and straight/heterosexuals.

\footnotetext{
${ }^{1}$ Mutually exclusive weight groups (underweight, normal, overweight, obese) were created using Centers for Disease Control and Prevention guidelines. The underweight group was excluded from multivariate analyses due to its small size.
} 


\section{Cancer Screening}

Colorectal cancer screening

- $55 \%$ of straight/heterosexual, $64 \%$ of gay/lesbian/homosexual, and $65 \%$ of bisexual adults ages 50 or older reported ever having a sigmoidoscopy or colonoscopy.

- Gay/homosexual men were more likely to have had a sigmoidoscopy/colonoscopy than heterosexual men (OR 1.87; 95\% Cl 1.05, $3.34)^{* *}$ while there was no difference between lesbian/homosexual and straight/heterosexual women.

- There were no statistically significant differences between bisexuals and straight/heterosexuals.

Prostate-specific antigen test

- $54 \%$ of straight/heterosexual, $42 \%$ of gay/ homosexual, and $51 \%$ of bisexual men ages 40 or older reported ever having a prostate-specific antigen test.

- There were no statistically significant differences between gay/lesbian/homosexuals and straight/heterosexuals or between bisexuals and straight/heterosexuals.

\section{Mammography}

- $58 \%$ of straight/heterosexual, $63 \%$ of lesbian/homosexual, and $33 \%$ of bisexual women ages 40 or older reported ever having a mammogram.

- There were no statistically significant differences between gay/lesbian/homosexuals and straight/heterosexuals or between bisexuals and straight/heterosexuals.

Cervical cancer screening

- $90 \%$ of straight/heterosexual, $89 \%$ of lesbian/homosexual, and $80 \%$ of bisexual women reported having a Pap test within the past three years.

- There were no statistically significant differences between gay/lesbian/homosexuals and straight/heterosexuals or between bisexuals and straight/heterosexuals.

\footnotetext{
${ }^{* *}$ Potentially unstable estimate; relative standard error $>0.30$ on the logit scale.
} 


\section{Chronic Health Conditions}

Diabetes

- $4 \%$ of straight/heterosexual and $3 \%$ of gay/lesbian/homosexual and bisexual adults reported that they ever had been told by a doctor or other healthcare provider that they had diabetes.

- There were no statistically significant differences between gay/lesbian/homosexuals and straight/heterosexuals or between bisexuals and straight/heterosexuals.

Heart disease

- $2 \%$ of straight/heterosexual, $3 \%$ of gay/lesbian/homosexual and bisexual adults reported that they ever had been told by a doctor or other healthcare provider that they had heart disease.

- Bisexuals were more likely to report having been told that they had heart disease than straight/heterosexuals (OR 2.86; 95\% Cl 1.07, 7.61).

- There were no statistically significant differences between gay/lesbian/homosexuals and straight/heterosexuals.

Asthma

- $15 \%$ of straight/heterosexual, $20 \%$ of gay/lesbian/homosexual, and $21 \%$ of bisexual adults reported that they ever had been told by a doctor or other healthcare provider that they had asthma.

- Gay/lesbian/homosexuals were more likely to report that they had asthma compared to straight/heterosexuals (OR 1.51; 95\% Cl 1.21, 1.88).

- There were no statistically significant differences between bisexuals and straight/heterosexuals. 
Figure 3: Health Outcome Differences: Chronic Health Conditions

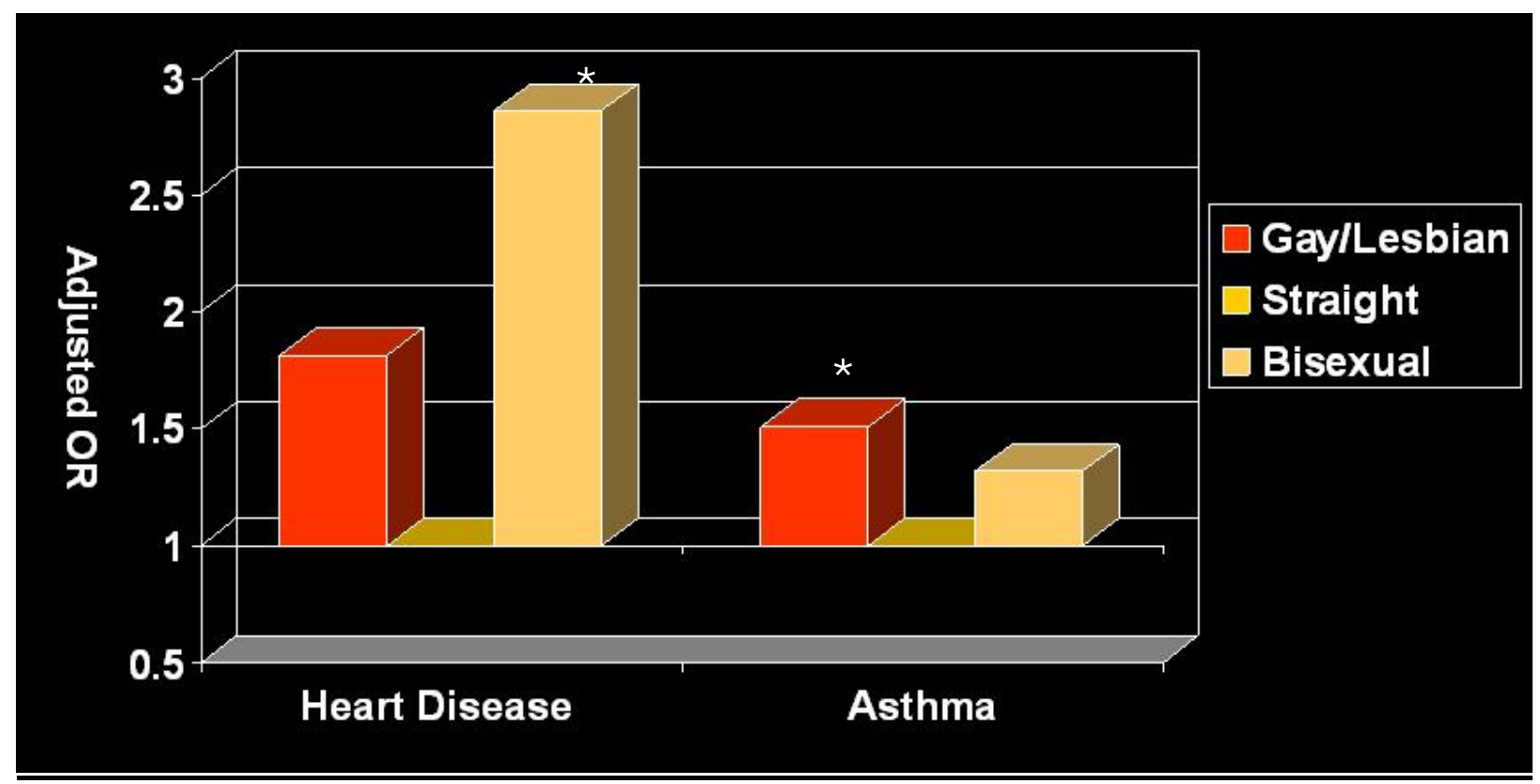

${ }^{*} P<0.05$, Referent group: straight 


\section{Mental Health}

Anxious mood

- $21 \%$ of straight/heterosexual, $25 \%$ of gay/lesbian/homosexual, and $45 \%$ of bisexual adults reported feeling tense or worried for more than 14 of the last 30 days.

- Gay/lesbian/homosexuals were more likely to report feeling tense or worried than straight/heterosexuals (OR 1.40; 95\% Cl 1.02, 1.92).

- Bisexuals were more likely to report feeling tense or worried than straight/heterosexuals (OR 3.10; $95 \% \mathrm{Cl} 2.06,4.65)$.

Depressed mood

- $16 \%$ of straight/heterosexual and gay/lesbian/homosexual and $29 \%$ of bisexual adults reported feeling sad or blue for more than 14 of the last 30 days.

- Bisexuals were more likely to report feeling sad or blue than straight/heterosexuals (OR 2.60; 95\% Cl 1.60, 4.21).

- There were no statistically significant differences between gay/lesbian/homosexuals and straight/heterosexuals.

\section{Suicide}

- $3 \%$ of straight/heterosexual, $4 \%$ of gay/lesbian/homosexual, and $29 \%$ of bisexual adults reported that they seriously considered suicide in the prior 12 months.

- Bisexuals were more likely to report that they seriously considered suicide than straight/heterosexuals (OR 9.16; 95\% Cl 3.91, 21.46).

- There were no statistically significant differences between gay/lesbian/homosexuals and straight/heterosexuals. 


\section{Substance Use}

Tobacco smoking

- $21 \%$ of straight/heterosexual, $31 \%$ of gay/lesbian/homosexual, and $39 \%$ of bisexual adults reported that they were current smokers.

- The odds of being a current smoker (OR $2.47 ; 95 \% \mathrm{Cl} 1.95,3.12)$ or a former smoker (OR 1.67; 95\% Cl 1.34, 2.09) versus never smoking were greater among gay/lesbian/homosexuals compared to straight/heterosexuals.

- The odds of current versus never smoking were greater (OR 2.96, 95\% $\mathrm{Cl} 1.79$, 4.89) among bisexual women than straight/heterosexual women. Bisexual men were also more likely to be current versus never smokers (OR 2.10; $95 \% \mathrm{Cl} 1.13$, $3.89)^{* *}$ than straight/heterosexual men.

- There were no statistically significant differences between bisexuals and straight/heterosexuals on being a former smoker versus never smoking.

Alcohol

- $21 \%$ of straight/heterosexual, $27 \%$ of gay/lesbian/homosexual, and $22 \%$ of bisexual adults reported binge drinking (five or more drinks in one sitting) at some point in the last 30 days.

- Gay/lesbian/homosexuals were more likely to report binge drinking than straight/heterosexuals (OR 1.29; 95\% Cl 1.01, 1.64)*.

- There were no statistically significant differences bisexuals and straight/heterosexuals.

Illicit drugs

- $8 \%$ of straight/heterosexual, $17 \%$ of gay/lesbian/homosexual, and $34 \%$ of bisexual adults reported illicit drug use at some point in the last 30 days.

- Gay/lesbian/homosexuals (OR 2.98; 95\% Cl 2.04, 4.37) were more likely to report illicit drug use than straight/heterosexuals.

- Bisexual women were more likely to report illicit drug use (OR 8.80; 95\% Cl 4.24, 18.30) than straight/heterosexual women, while there was no difference between bisexual and straight/heterosexual men.

\footnotetext{
${ }^{* *}$ Potentially unstable estimate; relative standard error $>0.30$ on the logit scale.
} 
Figure 4: Health Outcome Differences: Substance Use

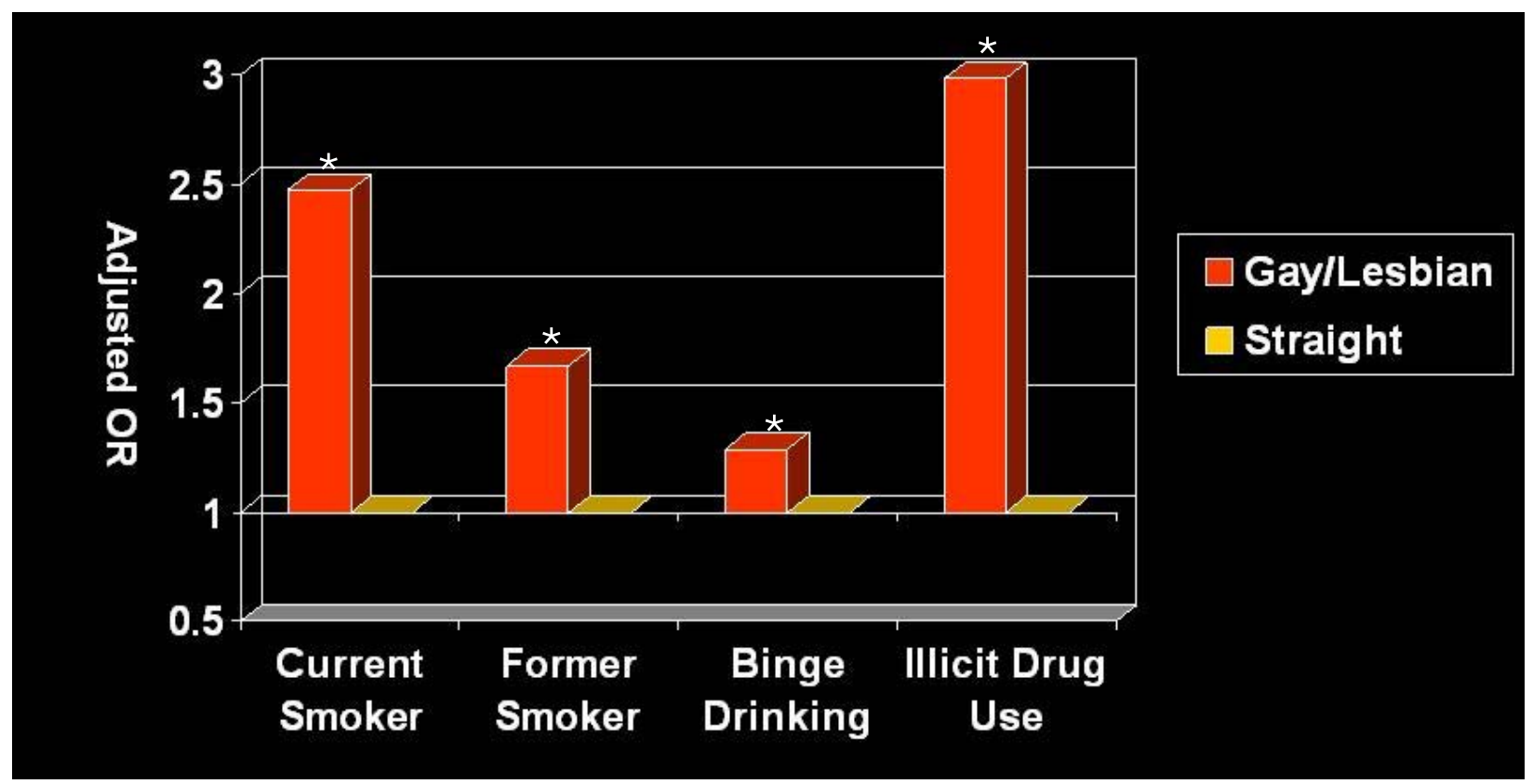

${ }^{\star} P<0.05$, Referent group: straight 


\section{Sexual Health}

HIV testing

- $43 \%$ of straight/heterosexual, $73 \%$ of gay/lesbian/homosexual, and $71 \%$ of bisexual adults reported ever obtaining a HIV test.

- The odds of lifetime HIV testing for lesbian/homosexual women were somewhat greater than those for straight/heterosexual women (OR 1.85, 95\% Cl 1.40, 2.44 ), while the odds for gay/homosexual men were much greater than the odds for straight/heterosexual men (OR 7.50; 95\% Cl 5.52, 10.18).

- Bisexuals were more likely to report a lifetime HIV test than straight/heterosexuals (OR 2.70; 95\% Cl 1.90, 3.84).

Condom use

- $46 \%$ of straight/heterosexual adults, $52 \%$ of gay/homosexual men, and $40 \%$ of bisexual adults, who reported oral, vaginal or anal sex with more than one partner in the last year and/or were not married or coupled, reported using a male or female condom at last oral, vaginal or anal sex.

- Gay/homosexual men were more likely to report condom use than straight/heterosexual men (OR 1.54; 95\% Cl 1.03, 2.31) ${ }^{* *}$.

- There were no statistically significant differences between bisexuals and straight/heterosexuals.

\footnotetext{
${ }^{* *}$ Potentially unstable estimate; relative standard error $>0.30$ on the logit scale.
} 


\section{Violence Victimization}

Sexual assault

Lifetime

- $13 \%$ of straight/heterosexual, $26 \%$ of gay/lesbian/homosexual, and $37 \%$ of bisexual adults reported ever being sexually assaulted.

- Gay/lesbian/homosexuals were more likely to report a lifetime experience of sexual assault than straight/heterosexuals (OR 2.91; 95\% Cl 2.04, 4.16).

- Bisexuals were more likely to report a lifetime experience of sexual assault than straight/heterosexuals (OR 3.68; 95\% Cl 2.18, 6.20).

12-month

- $2 \%$ of straight/heterosexual, $3 \%$ of gay/lesbian/homosexual, and $9 \%$ of bisexual adults reported being sexually assaulted in the prior 12 months.

- The odds of being sexually assaulted in the prior 12 months were greater for bisexuals than straight/heterosexuals (OR $4.0295 \% \mathrm{Cl} 1.32,12.21)^{* *}$.

- There were no statistically significant differences between gay/lesbian/homosexuals and straight/heterosexuals.

Intimate partner violence

\section{Lifetime}

- $18 \%$ of straight/heterosexual, $29 \%$ of gay/lesbian/homosexual, and $35 \%$ of bisexual adults reported ever having been threatened with physical violence or physically assaulted by an intimate partner.

- Bisexual women were more likely than straight/heterosexual women to report lifetime experiences of intimate partner violence (OR 7.98; 95\% Cl 1.52, 41.89) ${ }^{* *}$, while there was no difference between bisexual and straight/heterosexual men.

- There were no statistically significant differences between gay/lesbian/homosexuals and straight/heterosexuals.

12-month

- $4 \%$ of straight/heterosexual, $8 \%$ of gay/lesbian/homosexual, and $7 \%$ of bisexual adults reported being scared for their safety or physically assaulted by an intimate partner in the prior 12 months.

- There were no statistically significant differences between gay/lesbian/homosexuals and straight/heterosexuals or between bisexuals and straight/heterosexuals. 
Figure 5: Health Outcome Differences: Violence Victimization

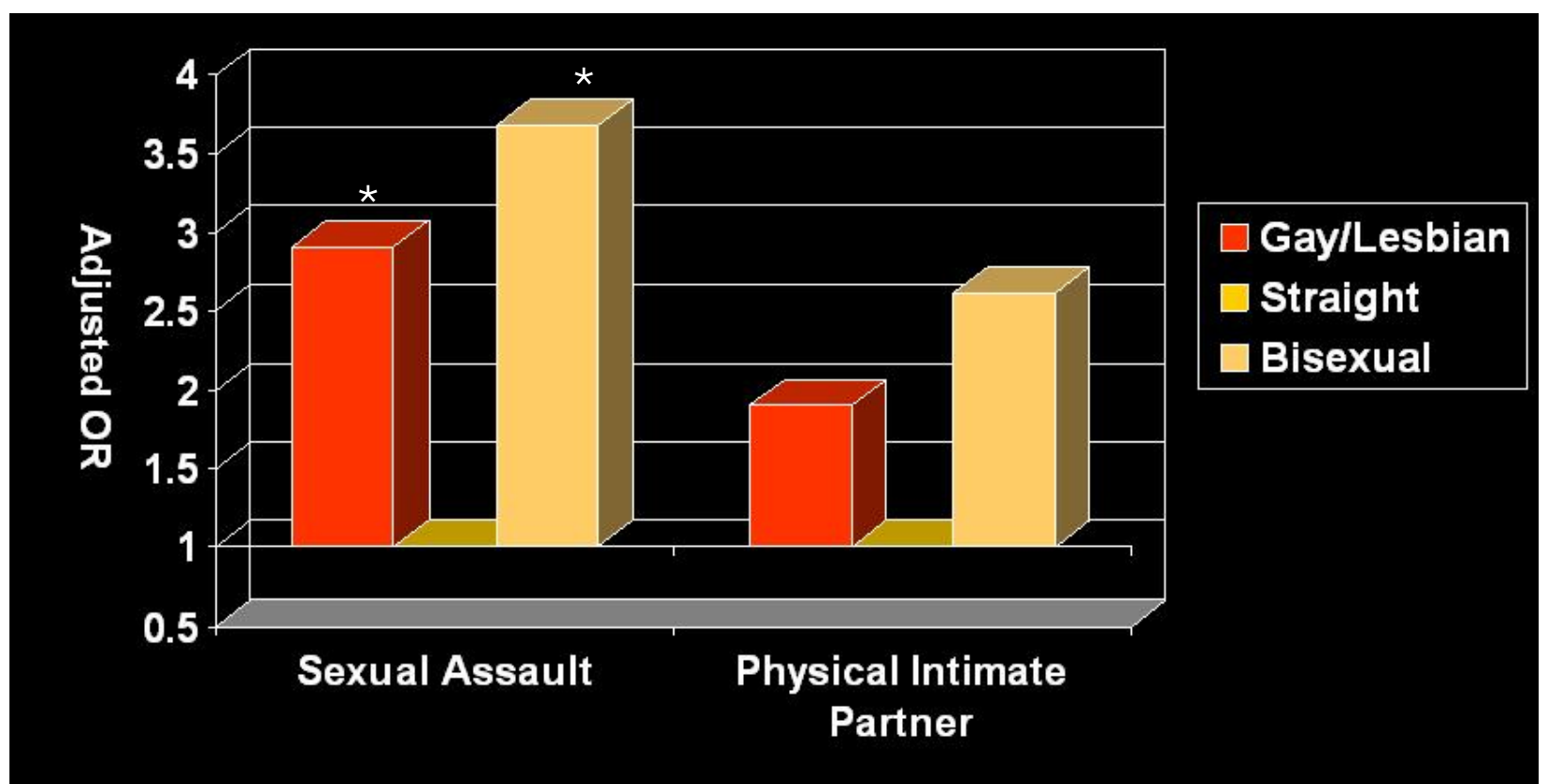

${ }^{*} P<0.05$, Referent group: straight 


\section{CONCLUSION}

This report is the first to present population-based estimates of health by sexual orientation identity for Massachusetts residents ages 18-64. It provides an overview of the health status of straight/heterosexual, gay/lesbian/homosexual, and bisexual adults for the years 2001-2006. Although no sexual orientation differences were observed in a few areas (prostate-specific antigen testing; lifetime mammography and 3-year cervical cancer screening; diabetes; and 12-month intimate partner violence victimization), differences between sexual orientation groups were more common. Sexual orientation disparities were observed with respect to access to health care, overall health status, cancer screening, chronic health conditions, mental health, substance use, including tobacco smoking, sexual health, and violence victimization. While gay/lesbian/homosexual adults evidenced poorer health and greater risk than straight/heterosexuals across several health domains, poorer health was observed most often for bisexuals.

The health profile of gay/lesbian/homosexual residents was poorer than that of heterosexual/straight residents on: self-reported health; disability-related activity limitation; asthma; current and past tobacco smoking versus never smoking; anxious mood, 30-day binge drinking and illicit drug use; and lifetime sexual assault victimization. In addition, lesbian/homosexual women were more likely to be obese than their heterosexual/straight female peers.

Bisexual residents faired worse than heterosexual/straight residents in terms of: access to health insurance, as well as medical and dental providers; heart disease; anxious and depressed moods and 12-month suicidal ideation; current tobacco smoking, and lifetime and 12-month sexual assault victimization. In addition, bisexual women were more likely to report disability-related activity limitation, 30-day illicit drug use, and lifetime intimate partner violence victimization than heterosexual/straight women.

Gay/lesbian//homosexuals and bisexuals appeared to be engaged in more health protective behavior than straight/heterosexuals in a few health domains. Gay/lesbian/homosexuals and bisexuals were more likely than heterosexuals to have been tested for HIV than their straight/heterosexual counterparts. Gay/homosexual men were less likely to be obese or overweight compared to straight/heterosexual men. They were also more likely to obtain lifetime colorectal cancer screening and to report recent condom use. Findings of relatively higher lifetime rates of HIV testing by gay/homosexual and bisexual men and higher rates of condom use by gay/homosexual men are encouraging due to the disproportionate burden of HIVIAIDS on these populations. However, absolute levels of health promoting behavior may be inadequate given the higher prevalence of sexually transmitted infections and HIVIAIDS among men who have sex with men (MDPH, 2008). 
There are limitations to the data in this report. First, the cross-sectional design does not allow us to identify trends over time even though changes occurred between 2001 and 2006 including same-sex marriage and the advent of health care reform. Further, all of the data are self-reported and there are no additional state-level sources of data (such as hospital discharge or outpatient) to confirm any of the findings. Finally, although the sample size is relatively robust to answer questions about disparities related to sexual orientation, there is insufficient power to analyze rare outcomes or to provide analysis based on race and ethnicity within sexual orientation identity groups.

The health domains selected for this report are not exhaustive, but rather, were picked to provide coverage of areas highlighted by Healthy People $2010^{2}$, the nation's blueprint for health. The amount of data collected across multiple years of the BRFSS also informed the choice of variables selected for this report. Additionally, this report does not address the health of transgender people as this question was added to the Massachusetts BRFSS in 2007. It is expected that a similar strategy of aggregating data from multiple years will be possible in order to make comparisons between transgender and non-transgender persons in the future. The current study highlights the utility of aggregating data collected consistently over time to provide population-based estimates of the health status and risk profile of sexual orientation and other minority groups.

Information on health disparities can be used to prioritize areas for intervention development and future research. Continued collection of sexual orientation data on the BRFSS survey, as well as other population-based surveys such as the Youth Risk Behavior Survey and the Youth Health Survey is imperative. On-going analysis of the Massachusetts BRFSS data is recommended to provide additional information about adult health defined by sexual orientation identity. As research continues, Massachusetts' public health programs should begin to address the sexual orientationrelated disparities identified in this report. An emphasis on the health needs of bisexuals in the Commonwealth is indicated by our findings.

\footnotetext{
${ }^{2}$ Healthy People 2010, the 10-year plan for improving the nation's health, includes objectives related to the elimination of health disparities based on sexual orientation (US DHHS, 2000). Appendix 3 provides summary information on the focus areas and objectives related to sexual orientation in Healthy People 2010.
} 
TABLE 1. Socio-demographic characteristics of 2001-2006 Massachusetts Behavioral Risk Factor Surveillance Survey participants $(N=38,910)$ ages $18-64$ by sexual orientation identity.

\begin{tabular}{|c|c|c|c|c|c|c|}
\hline & \multicolumn{2}{|c|}{$\begin{array}{l}\text { Straight/heterosexual } \\
\qquad\left(n^{*}=37,595\right)\end{array}$} & \multicolumn{2}{|c|}{$\begin{array}{l}\text { Gay/lesbian/homosexual } \\
(n=949)\end{array}$} & \multicolumn{2}{|c|}{$\begin{array}{l}\text { Bisexual } \\
(n=366)\end{array}$} \\
\hline & $\%^{\dagger}$ & $95 \% \mathrm{Cl}^{\ddagger}$ & $\%$ & $95 \% \mathrm{Cl}$ & $\%$ & $95 \% \mathrm{Cl}$ \\
\hline Age & 97.05 & 96.8297 .28 & 1.91 & $1.74,2.08$ & 1.04 & $0.88,1.20$ \\
\hline Age & 14.97 & $14.29,15.66$ & 13.49 & $8.90,18.09$ & 41.11 & $32.94,49.27$ \\
\hline $25-34$ & 21.86 & $21.27,22.46$ & 19.27 & $15.63,22.92$ & 23.04 & $17.35,28.73$ \\
\hline $35-44$ & 25.33 & $24.76,25.90$ & 30.65 & $26.81,34.48$ & 17.96 & $13.02,22.91$ \\
\hline $45-54$ & 21.87 & $21.34,22.40$ & 24.55 & $21.12,27.98$ & 11.39 & $7.78,15.01$ \\
\hline $54-64$ & 15.97 & $15.52,16.41$ & 12.03 & $9.55,14.51$ & 6.50 & $3.89,9.11$ \\
\hline \multicolumn{7}{|l|}{ Sex } \\
\hline Male & 49.37 & $48.66,50.09$ & 57.11 & $52.63,61.59$ & 35.02 & $27.58,42.47$ \\
\hline Female & 50.63 & $49.91,51.34$ & 42.89 & $38.41,47.37$ & 64.98 & $57.53,72.42$ \\
\hline \multicolumn{7}{|l|}{ Race-Ethnicity } \\
\hline White, non-Hispanic & 82.92 & $82.38,83.45$ & 86.04 & $82.99,89.09$ & 77.69 & $71.63,83.75$ \\
\hline Black, non-Hispanic & 3.85 & $3.60,4.10$ & 4.49 & $2.57,6.40$ & 3.90 & $1.66,6.14$ \\
\hline Hispanic & 8.97 & $8.54,9.40$ & 5.88 & $3.75,8.00$ & 11.68 & $7.12,16.25$ \\
\hline $\mathrm{API}$ or $\mathrm{Al}^{\#}$ & 4.27 & $3.98,4.56$ & 3.60 & $2.16,5.03$ & 6.73 & $2.74,10.72$ \\
\hline \multicolumn{7}{|l|}{ Relationship Status } \\
\hline Married & 58.32 & $57.60,59.03$ & 14.36 & $11.34,17.39$ & 21.09 & $15.50,26.69$ \\
\hline Widow, divorce, sep. & 12.35 & $11.97,12.73$ & 7.52 & $5.64,9.39$ & 15.22 & $9.69,20.74$ \\
\hline Never married & 24.56 & $23.87,25.26$ & 42.49 & $38.14,46.85$ & 46.46 & $38.78,54.15$ \\
\hline Coupled & 4.77 & $4.45,5.09$ & 35.62 & $30.96,40.28$ & 17.23 & $11.21,23.25$ \\
\hline \multicolumn{7}{|l|}{ Education } \\
\hline$<$ High school & 6.97 & $6.60,7.34$ & 4.16 & $2.17,6.16$ & 10.35 & $5.87,14.84$ \\
\hline High school/GED ${ }^{\&}$ & 24.16 & $23.53,24.78$ & 18.55 & $14.17,22.93$ & 21.46 & $14.54,28.37$ \\
\hline $1-3$ years college & 24.77 & $24.14,25.41$ & 21.67 & $17.93,25.41$ & 23.20 & $16.53,29.86$ \\
\hline$\geq 4$-year college & 44.10 & $43.41,44.79$ & 55.61 & $50.98,60.25$ & 45.00 & $37.49,52.51$ \\
\hline \multicolumn{7}{|l|}{ Employment Status } \\
\hline Employed & 74.26 & $73.63,74.89$ & 78.31 & $74.63,82.00$ & 56.94 & $49.27,64.60$ \\
\hline Unemployed & 10.13 & $9.72,10.54$ & 13.02 & $10.23,15.82$ & 21.52 & $15.02,28.01$ \\
\hline Not in workforce & 15.61 & $15.06,16.16$ & 8.66 & $5.91,11.42$ & 21.54 & $15.05,28.04$ \\
\hline \multicolumn{7}{|l|}{ Household Income } \\
\hline$<\$ 20,000$ & 9.15 & $8.76,9.55$ & 9.91 & $7.40,12.42$ & 19.81 & $14.06,25.56$ \\
\hline$\$ 20,000-34,999$ & 13.25 & $12.77,13.73$ & 14.78 & $11.66,17.91$ & 21.44 & $14.69,28.19$ \\
\hline$\$ 35,000-74,999$ & 29.76 & $29.13,30.39$ & 32.16 & $28.02,36.31$ & 24.17 & $18.59,29.74$ \\
\hline$\$>75,000$ & 36.06 & $35.38,36.74$ & 37.57 & $33.08,42.05$ & 23.50 & $16.36,30.65$ \\
\hline Misssing & 11.78 & $11.27,12.29$ & 5.58 & $3.49,7.66$ & 11.08 & $6.04,16.12$ \\
\hline $\begin{array}{l}\text { Number of subjects } \\
{ }^{+} \text {Weighted column prop } \\
{ }^{+} \text {Design-adjusted confi } \\
{ }^{*} \text { Asian, Pacific Islander } \\
\text { \& Graduate equivalency }\end{array}$ & ree & 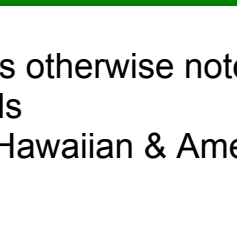 & ing & & & \\
\hline
\end{tabular}




\section{TABLE 2. Health profile of 2001-2006 ${ }^{\dagger \dagger}$ Massachusetts Behavioral Risk Factor Surveillance Survey participants $(\mathrm{N}=38,910)$ ages $18-64^{\S}$ by sexual orientation identity.}

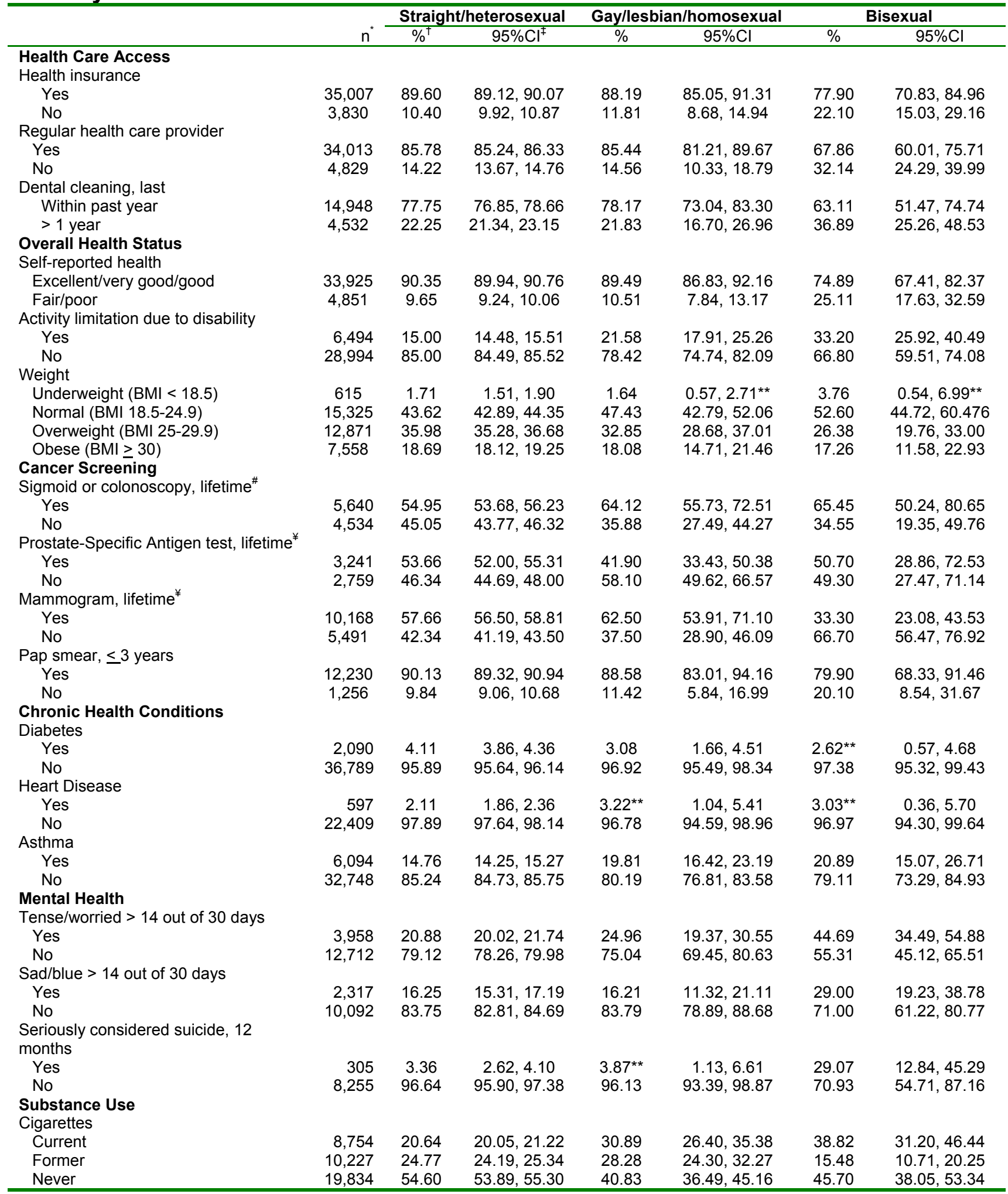




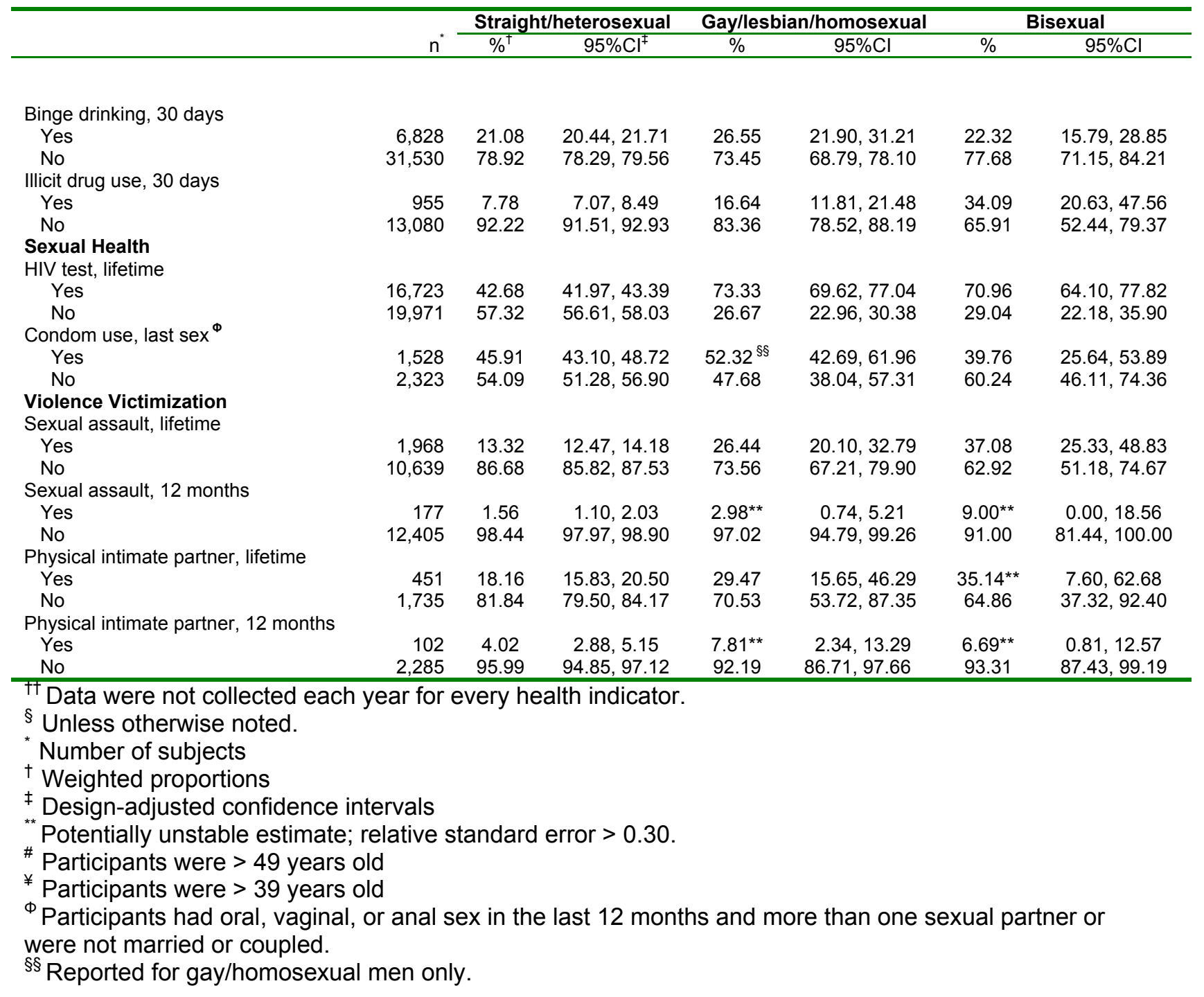


TABLE 3. Adjusted odds ratios comparing health characteristics of 18-64 year old gay/lesbian/homosexual and bisexual to straight/heterosexual participants $(\mathrm{N}=38,910)$ in the 2001-2006 Massachusetts Behavioral Risk Factor Surveillance Survey.

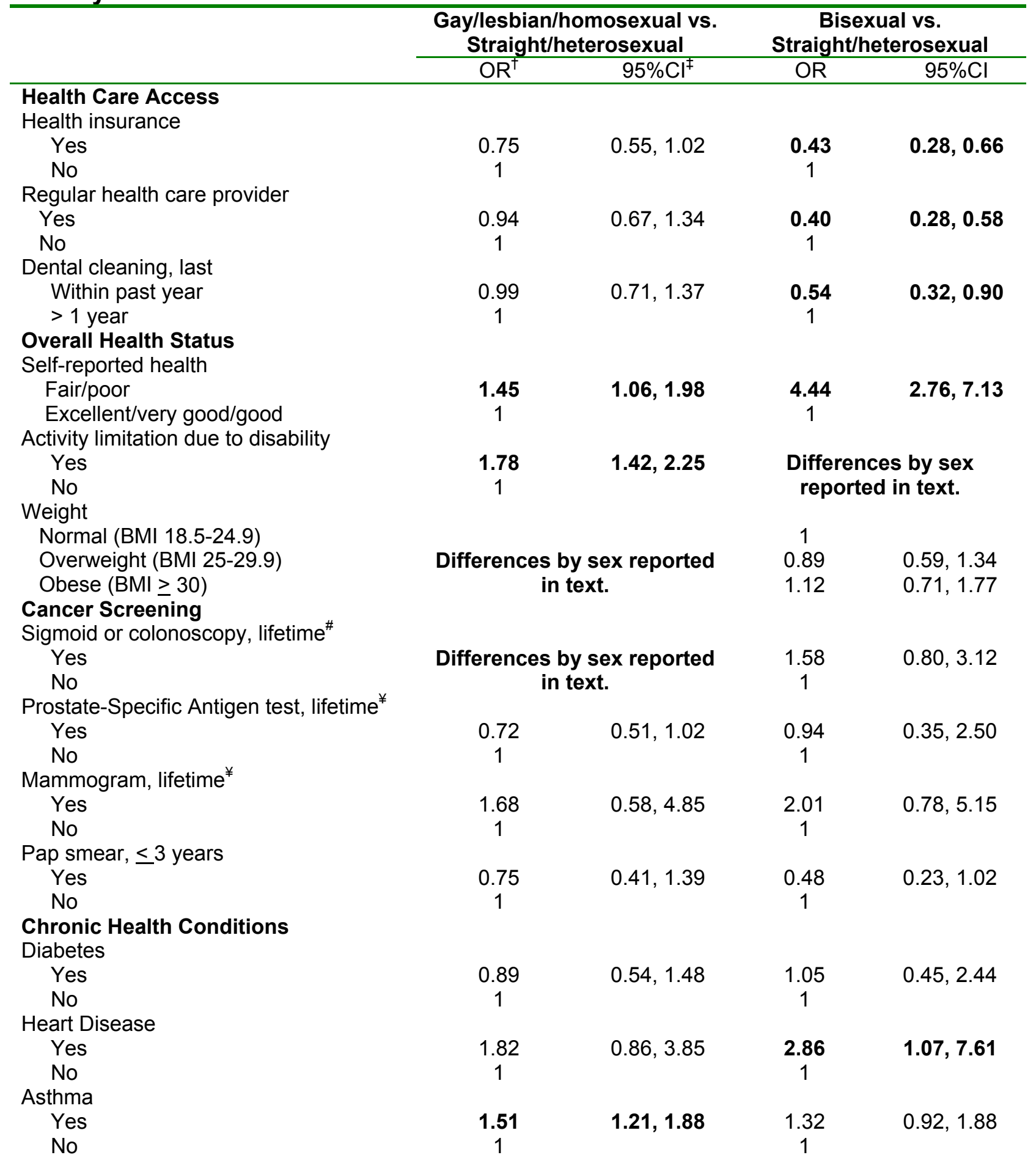




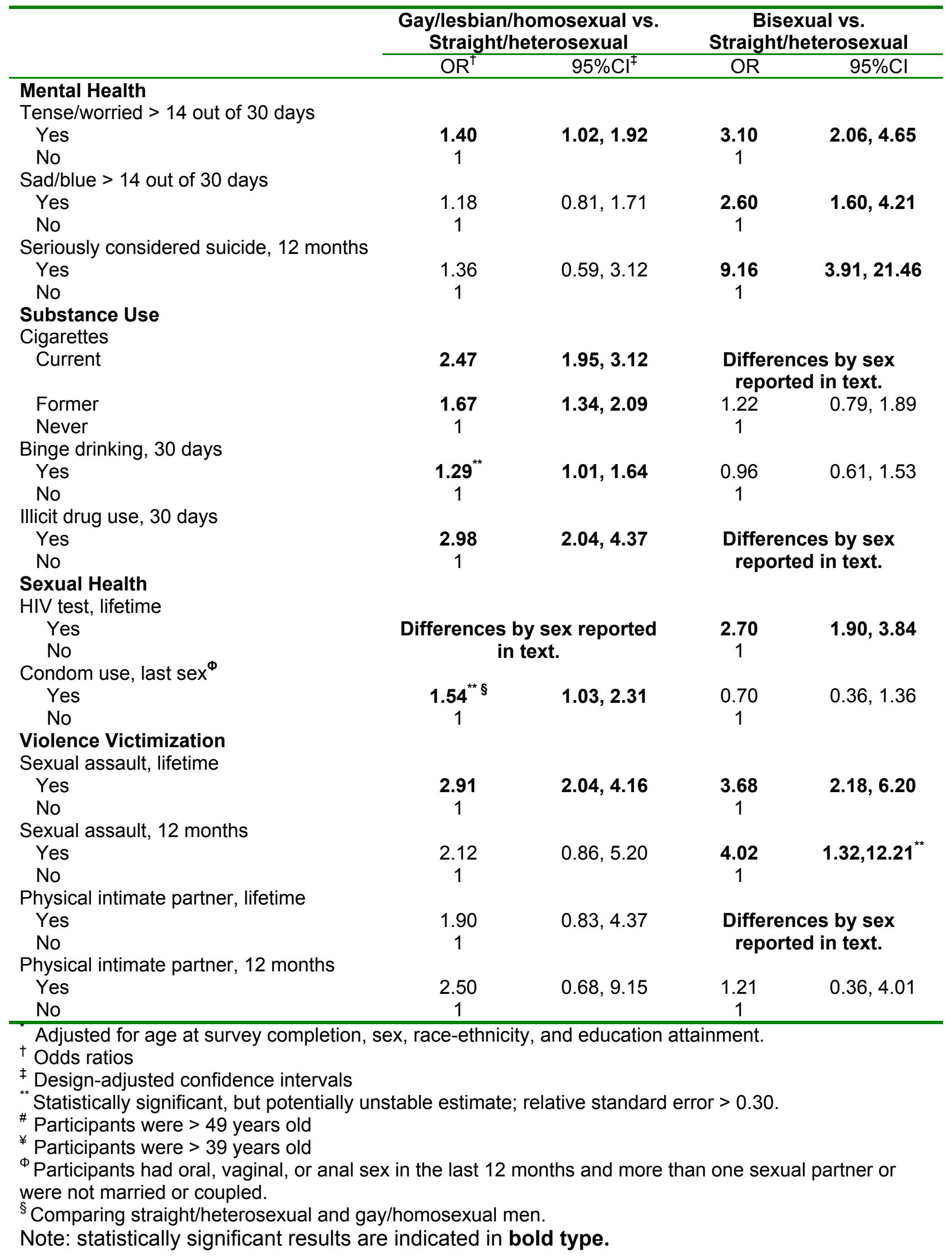




\section{Acknowledgements}

The Massachusetts Behavioral Risk Factor Surveillance System is overseen by the Massachusetts Department of Public Health (MDPH), Bureau of Health Information, Statistics, Research and Evaluation. Many individuals at the MDPH supported the development of this report, including Bruce Cohen, Susan Keyes, and Zi Zhang who facilitated access to the data and Cynthia Boddie-Willis, Michael Botticelli, Kevin Cranston, Luigi Ferrer, and Angela Nannini who provided helpful feedback on earlier drafts. The MDPH HIVIAIDS Bureau and The Williams Project/Ford Foundation funded the development of this report. Lastly, we wish to acknowledge the Massachusetts residents who generously took part in the BRFSS surveys. 


\section{References}

Bye, L., Gruskin, E., Greenwood, G., Albright, V, Krotki, K. (2005). California lesbians, gays, bisexuals, and transgender (LGBT) tobacco use survey - 2004. Sacramento, CA: California Department of Health Services. Retrieved August 26, 2008, from http://ww2.cdph.ca.gov/programs/tobacco/documents/ctcp-Igbttobaccostudy.pdf.

Centers for Disease Control and Prevention. About BMI for Adults. Retrieved August 7, 2008, from http://www.cdc.gov/nccdphp/dnpa/healthyweight/assessing/bmi/adult BMI/about adult BMI.htm

Centers for Disease Control and Prevention. (2006). Behavioral Risk Factor Surveillance System Operational and User's Guide. Version 3.0. Retrieved August 26, 2008, from ftp://ftp.cdc.gov/pub/data/brfss/userguide.pdf

Cochran, S.D. \& Mays, V.M. (2007). Physical health complaints among lesbians, gay men, and bisexual and homosexually experienced heterosexual individuals: Results from the California Quality of Life Survey. American Journal of Public Health, 97(11): 2048 - 2055.

Cochran, S.D., Mays, V.M., Bowen, D., Gage, S., Bybee, D., Roberts, S.J., Goldstein, R.S., Robison, A., Rankow, E.J., \& White, J. (2000). Cancer-related risk indicated and preventive screening behaviors among lesbians and bisexual women. American Journal of Public Health, 91(4): 591-597.

Cochran, S.D., Sullivan, J.G., \& Mays, V.M. (2003). Prevalence of mental disorders, psychological distress and mental health services use among lesbian, gay, and bisexual adults in the United States. Journal of Consulting and Clinical Psychology, 71: 53-61.

Diamant, A.L., Wold, C., Spritzer, K., \& Gelberg, L. (2000). Health behaviors, health status, and access to and use of health care: A population-based study of lesbian, bisexual, and heterosexual women. Archives of Family Medicine, 9: 1043-1051.

Gay and Lesbian Medical Association (GLMA) and LGBT health experts. (2001). Healthy People 2010 companion document for lesbian, gay, bisexual, and transgender (LGBT) health. San Francisco: Author. Retrieved May 21, 2007, from http://www.glma.org

Gilman, S.E., Cochran, S.D., Mays, V.M., Hughes, M., Ostrow, D., \& Kessler, R.C. (2001). Risk of psychiatric disorders among individuals reporting same-sex sexual partners in the National Comorbidity Study. American Journal of Public Health, 91(6): 933-937.

Greenwood, G.L., Paul, J.P., Pollack, L.M., Binson, D., Catania, J.A., Chang, J., Humfleet, G., \& Stall, R. (2005). Tobacco use and cessation among a household-based sample of US urban men who have sex with men, American Journal of Public Health, 95(1): 145-151.

Heck, J.E., Sell, R.L., \& Gorin, S.S. (2006). Health care access among individuals involved in same-sex relationships. American Journal of Public Health, 96(6): 1111-1118. 
Lampinen, T. M., Chan, K., Anema, A., Miller, M. L., Schilder, A. J., Schechter, M. T., Hogg, R. S., \& Strathdee, S. A. (2008). Incidence of and risk factors for sexual orientationrelated physical assault among young men who have sex with men. American Journal of Public Health, 98(6): 1028 - 1035.

Makadon, H.J., Mayer, K.H., Potter, J., \& Goldhammer, H. (Eds.). (2007). The Fenway guide to lesbian, gay, bisexual and transgender health. Philadelphia: American College of Physicians.

Massachusetts Department of Public Health (MDPH). (2001). Behavioral Risk Factor Survey 2001 Questionnaire. Health Survey Program, Behavioral Risk Factor Surveillance System. Retrieved August 26, 2008, from http://www.mass.gov/Eeohhs2/docs/dph/behavioral risk/survey 01.pdf

Massachusetts Department of Public Health (MDPH). (2001-2006). A Profile of Health Among Massachusetts Adults, Results from the Behavior Risk Factor Surveillance System. Annual report. Health Survey Program, Bureau of Health Information, Statistics, Research, and Evaluation. Boston: Author.

Massachusetts Department of Public Health (MDPH). (2008). Inequitable Impact: The HIVIAIDS Epidemic Among Gay and Bisexual Men and Other Men Who Have Sex with Men in Massachusetts. HIVIAIDS Bureau. Boston: Author.

Meyer, I. \& Northridge, M., (Eds.). (2007). The health of sexual minorities: Public health perspectives on lesbian, gay, bisexual, and transgender populations. New York: Springer.

Moracco, K.E., Runyan, C.W., Bowling, J.M., \& Earp, J.A. (2007). Women's experiences with violence: A national study. Women's Health Issues, 17(1): 3-12.

SAS Institute Inc. (2003). SAS v9.1. Cary, NC.

Sell, R.L. \& Becker, J.B. (2001). Sexual orientation data collection and progress toward Healthy People 2010. American Journal of Public Health, 91(6): 876-883.

US DHHS. (2000). Healthy People 2010: Understanding and improving health. (2 ${ }^{\text {nd }}$ ed.) Washington, DC: U.S. Government Printing Office.

Wolitski, R.J., Stall, R., \& Valdiserri, R.O. (Eds.). (2008). Unequal opportunity: Health disparities affecting gay and bisexual men in the United States. Oxford: Oxford University Press. 


\section{Appendix 1}

\section{Sexual Orientation Identity Non-Response 2001-2006}

Non-response on the sexual orientation identity item due to refusal was the highest in 2001 (5.7\%), the first year that the question was asked, and dropped to approximately $3 \%$ in subsequent years. The proportion stating that they "didn't know" remained stable over time. In 2001, the sexual orientation identity measure was located halfway into the survey and proceeded questions about HIV knowledge and testing behavior. In subsequent years, sexual orientation identity appeared in the demographic section, about one-third of the way into the survey. Interviewer comfort and/or location in the survey may have impacted refusal rates.

Information about non-response on other survey items may help readers to contextualize non-response on sexual orientation identity: $5.6 \%$ of participants declined to provide annual income information while another $5.6 \%$ reported that they didn't know their household income; $0.7 \%$ declined to provide information about their race and $0.4 \%$ stated that they didn't know the answer; and a total of $12.9 \%$ of participants did not answer a question about whether or not they were sexually active in the last 12 months. 


\section{Appendix 2}

\section{Terms and Definitions*}

The BRFSS data are weighted to take into account differences in probabilities of selection due to the telephone number, the number of telephones in a household, and the number of adults in a household. Adjustments are also made to account for non-response and non-coverage of households without telephones. All the weighting factors are multiplied together to get the final weight for each participant so that the weighted BRFSS data represents the adult population of Massachusetts.

The crude percentage is the weighted proportion of participants in a particular category. All percentages reported in this report refer to crude percentages. In this report, the crude percentage reflects the burden of a certain health status indicator in a specific group of the population (e.g., gay/lesbian/homosexual, straight/heterosexual, etc.).

A $95 \%$ confidence interval $(95 \% \mathrm{Cl})$ is a range of values within which the true population value is likely to lie. The width of the interval is determined by the degree of variability in the data. The confidence interval indicates the precision of an estimate; the wider the interval, the less precise the estimate. The $95 \%$ confidence intervals used in this report for crude percentages and adjusted odds ratios are indicators of reliability (or stability) of the estimate. Estimates based on small numbers of participants are less reliable than those based on larger numbers of participants. For this reason, several years worth of data have been aggregated.

The National Center for Health Statistics recommends suppressing potentially unstable estimates, defined as those where the ratio of standard error to the estimate itself exceeds $30 \%$ (relative standard error of greater than $30 \%$ ). In a few instances, these data are reported and are noted as in violation of this recommendation.

* These terms and definitions are based upon material from the 2006 BRFSS report, "A Profile of Health Among Adults, 2006 - Results from the Behavior Risk Factor Surveillance System, pp.9-11. Available online at http://www.mass.gov/Eeohhs2/docs/dph/behavioral risk/report 2006.pdf 


\section{Appendix 3}

HP2010 Objectives Referencing Sexual Orientation*

\begin{tabular}{|c|c|c|}
\hline \multicolumn{3}{|c|}{ Healthy People 2010 Objectives Related to Sexual Orientation } \\
\hline HP 2010 Focus Area** & HP 2010 Objective (Summary)** & $\begin{array}{l}\text { Currently asked } \\
\text { in } 2006 \text { MA BRFS } \\
\text { survey? Or, if not, } \\
\text { through another } \\
\text { population-based } \\
\text { survey? }\end{array}$ \\
\hline \multirow[t]{3}{*}{$\begin{array}{l}\text { 1. Access to quality } \\
\text { health care }\end{array}$} & $\begin{array}{l}\text { 1. Increase the proportion of persons with } \\
\text { health insurance. }\end{array}$ & Yes \\
\hline & $\begin{array}{l}\text { 3. Increase the proportion of persons } \\
\text { appropriately counseled about health } \\
\text { behaviors }\end{array}$ & $\begin{array}{l}\text { Limited. There } \\
\text { are questions in } \\
2006 \text { about } \\
\text { providers } \\
\text { talking to } \\
\text { patients about } \\
\text { prostate cancer } \\
\text { screening and } \\
\text { cigarette } \\
\text { smoking. }\end{array}$ \\
\hline & $\begin{array}{l}\text { 4. Increase the proportion of persons who have } \\
\text { a specific source of ongoing care }\end{array}$ & Yes \\
\hline \multirow[t]{2}{*}{$\begin{array}{l}\text { 7. Educational and } \\
\text { community-based } \\
\text { programs }\end{array}$} & $\begin{array}{l}\text { 3. Increase the proportion of college and } \\
\text { university students who receive information } \\
\text { from their institutions on each of the } 6 \text { priority } \\
\text { health-risk behavior areas }\end{array}$ & No \\
\hline & $\begin{array}{l}\text { 12. Increase the proportion of older adults who } \\
\text { have participated during the preceding year in } \\
\text { at least one organized health promotion } \\
\text { activity }\end{array}$ & No \\
\hline 9. Family planning & $\begin{array}{l}\text { 11. Increase the proportion of young adults } \\
\text { who have received formal instruction on } \\
\text { reproductive health issues before age } 18\end{array}$ & $\begin{array}{l}\text { No, YRBS asks } \\
\text { about HIV and } \\
\text { "Health" } \\
\text { Education }\end{array}$ \\
\hline \multirow[t]{2}{*}{ 13. HIV } & 1. Reduce AIDS among adolescents and adults & $\begin{array}{l}\text { No, through } \\
\text { HIV/AIDS } \\
\text { Surveillance }\end{array}$ \\
\hline & $\begin{array}{l}\text { 6. Increase the proportion of sexually active } \\
\text { persons who use condoms }\end{array}$ & Yes \\
\hline $\begin{array}{l}\text { 14. Immunizations and } \\
\text { infectious disease }\end{array}$ & 6. Reduce hepatitis A prevalence & No \\
\hline
\end{tabular}




\begin{tabular}{|c|c|c|}
\hline \multirow[t]{3}{*}{$\begin{array}{l}\text { 15. Injury and violence } \\
\text { prevention }\end{array}$} & $\begin{array}{l}\text { 34. Reduce the rate of physical assault by } \\
\text { current or former intimate partners }\end{array}$ & Yes \\
\hline & $\begin{array}{l}\text { 35. Reduce the annual rates of rape and } \\
\text { attempted rape }\end{array}$ & Yes \\
\hline & 36. Reduce sexual assault other than rape & Yes \\
\hline \multirow[t]{2}{*}{$\begin{array}{l}\text { 18. Mental health and } \\
\text { mental disorders }\end{array}$} & $\begin{array}{l}\text { 2. Reduce the rate of suicide attempts by } \\
\text { adolescents }\end{array}$ & No, YRBS \\
\hline & $\begin{array}{l}\text { 9. Increase the proportion of adults with } \\
\text { mental disorders who receive treatment }\end{array}$ & $\begin{array}{l}\text { No (question re } \\
\text { diagnosis only) }\end{array}$ \\
\hline \multirow[t]{2}{*}{$\begin{array}{l}\text { 25. Sexually } \\
\text { transmitted diseases }\end{array}$} & $\begin{array}{l}\text { 3. Eliminate sustained domestic transmission } \\
\text { of primary and secondary syphilis }\end{array}$ & No \\
\hline & $\begin{array}{l}\text { 11. Increase the proportion of adolescents who } \\
\text { abstain from sexual intercourse or use condo s } \\
\text { if currently sexually active }\end{array}$ & No, YRBS \\
\hline \multirow[t]{6}{*}{ 26. Substance abuse } & $\begin{array}{l}\text { 9. Increase the age and proportion of } \\
\text { adolescents who remain alcohol and drug free }\end{array}$ & No, YRBS \\
\hline & 10. Reduce past-month use of illicit substances & Yes \\
\hline & $\begin{array}{l}\text { 11. Reduce the proportion of persons engaging } \\
\text { in binge drinking of alcoholic beverages }\end{array}$ & Yes \\
\hline & $\begin{array}{l}\text { 15. Reduce the proportion of adolescents who } \\
\text { use inhalants }\end{array}$ & No, YRBS \\
\hline & $\begin{array}{l}\text { 16. Increase the proportion of adolescents who } \\
\text { disapprove of substance abuse }\end{array}$ & No, YRBS \\
\hline & $\begin{array}{l}\text { 17. Increase the proportion of adolescents who } \\
\text { perceive great risk associated with substance } \\
\text { abuse }\end{array}$ & No, YRBS \\
\hline \multirow[t]{7}{*}{ 27. Tobacco use } & 1. Reduce tobacco use by adults & Yes \\
\hline & 2. Reduce tobacco use by adolescents & No, YRBS \\
\hline & $\begin{array}{l}\text { 4. Increase the average age of first use of } \\
\text { tobacco products by adolescents and young } \\
\text { adults }\end{array}$ & No, YRBS \\
\hline & $\begin{array}{l}\text { 5. Increase smoking cessation attempts by } \\
\text { adult smokers }\end{array}$ & Yes \\
\hline & $\begin{array}{l}\text { 7. Increase tobacco use cessation attempts by } \\
\text { adolescent smokers }\end{array}$ & No, YRBS \\
\hline & $\begin{array}{l}\text { 10. Reduce the proportion of nonsmokers } \\
\text { exposed to environmental tobacco smoke }\end{array}$ & Yes \\
\hline & $\begin{array}{l}\text { 17. Increase adolescents' disapproval of } \\
\text { smoking }\end{array}$ & No, YRBS \\
\hline
\end{tabular}

*Information from this table summarized from Table 1 in Sell \& Becker, 2001.

**Numbering within focus areas and objectives matches numbering in Healthy People 2010

***The 2006 BRFSS also asks participants whether a medical provider has asked them about their sexual behavior and alcohol and drug use. 